\title{
A Generalized Capillary Imbibition Model for Porous Media in Tight Reservoirs
}

\author{
Zhiyuan Wang $\mathbb{D}^{1,2}$ Zhengming Yang $\mathbb{D}^{2,3}$ Yunhong Ding, ${ }^{3}$ Wei Lin $\mathbb{D C}^{1,2}$ Ying He, ${ }^{2,3}$ \\ and Xiaolang Duan ${ }^{4}$ \\ ${ }^{1}$ University of Chinese Academy of Sciences, Beijing 100049, China \\ ${ }^{2}$ Institute of Porous Flow and Fluid Mechanics, Chinese Academy of Sciences, Langfang 065007, China \\ ${ }^{3}$ Research Institute of Petroleum Exploration and Development, Beijing 100083, China \\ ${ }^{4}$ Production Operation Office, Production Branch of Southwest Oil and Gas Gield, Petrochina, Chengdu 610051, China
}

Correspondence should be addressed to Wei Lin; ucaslinwei@126.com

Received 6 June 2018; Revised 22 August 2018; Accepted 10 September 2018; Published 8 October 2018

Academic Editor: Annan Zhou

Copyright ( 2018 Zhiyuan Wang et al. This is an open access article distributed under the Creative Commons Attribution License, which permits unrestricted use, distribution, and reproduction in any medium, provided the original work is properly cited.

Capillary imbibition models have been widely studied in oil and gas development field over the past decades. However, the existing models applied to the tight reservoirs rarely take fluid flow resistance and apparent viscosity into account. To investigate the capillary imbibition characteristics of fluids in tight porous media, a generalized capillary imbibition model considering the flow resistance and apparent viscosity of fluids in tight porous media is derived. By comparing with the results of other capillary imbibition models and experimental data, the derived capillary imbibition model is verified. In addition, compared with the conventional capillary imbibition models, the derived capillary imbibition model is more consistent with the experimental results and has a wider applicability. The imbibition distance of water in tight reservoirs can also be obtained using the derived capillary imbibition model, which will facilitate the study on water injection development in tight oil and gas reservoirs.

\section{Introduction}

With the application of large-scale volume fracturing technology in the development of tight oil and gas, the imbibition is playing an increasingly important role in enhancing the recovery of tight reservoirs [1-5]. As the capillary imbibition of liquids in porous media has been utilized extensively in reservoir development, paper treatment, and antiseepage of the dam and other fields [6-11], the subject on imbibition had received wide attention and research from the last century. Bell and Cameron [12], Lucas [13], and Washburn [14] have put forward capillary imbibition equations, based on Hagen-Poseuille (H-P) flow in a cylindrical tube model, which laid the foundation for the development of imbibition model. Due to the complexity of natural porous media, the classical LW equation has been modified by considering the different structural characteristics of porous media [15-21].
Dullien et al. [15] derived the equation of capillary rising rate in sandstone samples, based on three-dimensional straight pore structure network model which is composed of a repeat capillary element with a step change. Hammecker et al. [16] proposed a new cylindrical model to describe capillary imbibition in porous sedimentary rocks, consisting of a periodic succession of a single hollow spherical element. Benavente et al. [17] modified the LW equation by introducing the correction factors of the pore shape and tortuosity to describe the pore space of natural rocks. Fries and Dreyer [18] derived an analytic solution for the capillary rise of liquids in a cylindrical tube or a porous medium in terms of height $h$ as a function of time $t$. Cai [19-21] introduced the fractal theory into the capillary imbibition model, and he derived a new generalized capillary imbibition model through the improved $\mathrm{H}-\mathrm{P}$ equation and the modified Laplace-Young (L-Y) equation, which takes into account the size and shape of the pores, the tortuosity of random porous media, and the initial wetting- 
phase saturation [8]. However, these models cannot be well applied to the capillary imbibition of tight rocks, because tight rock is a kind of complex porous media, which has fine porethroat structure and obvious fluid-solid effect.

So far, it is generally believed that Darcy flow only occurs under certain conditions, and non-Darcy flow (nonlinear percolation) is more common [22]. For example, Darcy's law cannot accurately describe the porous flow of high viscosity crude oil in the reservoir. And for the flow in lowpermeability rocks, especially for that in tight rocks, the Darcy's law is not applicable as well, due to the complex pore-throat structure and strong fluid-solid action of tight reservoir. In terms of non-Darcy flow, scholars have studied it by means of direct experiments, numerical derivation, or combined conceptual models. And a series of results have been obtained in the study of nonlinear percolation mechanism [22-28]. Miller and Low found the presence of a threshold gradient for water flow in clays and proved that no flow occurs when the hydraulic gradient is below the threshold gradient [23]. Huang et al. expounded the characteristics of nonlinear percolation in low-permeability porous media according to experimental data. In his opinion, the porous media have selectivity for the passage of fluids, and the apparent viscosity of the same fluid in different sizes of pores is different, which makes the seepage law of low-permeability reservoirs obey nonlinear law with a start-up pressure gradient. Therefore, the characteristics of the nonlinear seepage cannot be ignored in the study of imbibition of tight cores [22].

In this paper, a new generalized capillary imbibition model is derived by considering the resistance of fluids in tight porous media and the change of apparent viscosity in tight pore space on the basis of previous studies.

\section{Characteristics of Porous Flow in Tight Cores}

Tight core is defined as the core collected from the tight reservoir, whose air permeability is less than $1 \times 10^{-3} \mu \mathrm{m}^{2}$, and the pore-throat radius of tight core is mainly distributed in the range from $10 \mathrm{~nm}$ to $1000 \mathrm{~nm}$ [29]. We assume the core as a capillary model with the same average pore radius.

2.1. Flow Resistance of Fluids in Tight Cores. A large number of experiments $[30,31]$ indicate that the fluid flow in tight cores follows the nonlinear law with a start-up pressure gradient $\left(G_{\mathrm{a}}\right)$, as shown in Figure 1. Figure 1 illustrates that the fluid does not flow when the pressure gradient is less than a certain value, and the pressure gradient $\left(G_{\mathrm{a}}\right)$ is the minimum resistance gradient that the fluid needs to overcome when flowing in the tight core. When the pressure gradient is greater than $G_{\mathrm{a}}$, the curve in Figure 1 is a concave trend, because the fluid begins to overcome fluid-solid force to move. When the pressure gradient is greater than a certain value $\left(G_{\mathrm{b}}\right)$, the curve in Figure 1 becomes a straight line, this is because most of the fluid in pores is fully utilized and start flowing. The pressure gradient $\left(G_{\mathrm{b}}\right)$ is called the maximum resistance gradient. Hence, the fluid flow resistance in porous media should be fully considered when it comes to seepage of fluids in tight reservoirs.

2.2. Apparent Viscosity of Fluids in Tight Cores. According to the study by Huang [22], the fluid is divided into two parts: boundary fluid and bulk fluid. Moreover, the boundary fluid takes up too large space of tight cores to ignore. The apparent viscosity of fluid in tight core is available under the expression

$$
\mu_{\mathrm{c}}=A \mu_{1}+(1-A) \mu=\left[\left(\frac{\mu_{1}}{\mu}-1\right) A+1\right] \mu=\xi \mu,
$$

where $\mu_{\mathrm{c}}$ is the apparent viscosity of fluid in tight core (MPa-s), $A$ is the ratio of volume of boundary fluid and volume of total fluid in tight core, $\mu_{1}$ is the average viscosity of boundary fluid in tight core (MPa.s), $\mu$ is the viscosity of bulk fluid (MPa.s), and $\xi$ is the apparent viscosity coefficient.

\section{Mathematical Model}

3.1. Modified H-P and L-YEquations. According to the study by Cai [8], we can get the modified H-P and L-Y equations, respectively, for tortuous capillaries with variably shaped apertures:

$$
\begin{gathered}
q=\frac{\pi\left(\alpha r_{\mathrm{h}}\right)^{4} \Delta P}{8 \mu \tau L_{0}}=\frac{\pi r^{4} \Delta P}{8 \mu \tau L_{0}}, \\
P_{\mathrm{c}}=\frac{2 \sigma \cos \theta}{\alpha r_{\mathrm{h}}}=\frac{2 \sigma \cos \theta}{r},
\end{gathered}
$$

where $L_{0}$ is the length of the capillary tube, $m, \tau$ is the tortuosity, $\Delta P$ is the drop pressure along flow direction, $\mathrm{MPa}, r_{\mathrm{h}}=2 A_{\mathrm{C}} / C, A_{\mathrm{C}}$ is the capillary's cross-sectional area, $C$ is the capillary's circumference of cross-sectional, $r$ is the equivalent pore radius, $\mu \mathrm{m}, \alpha$ is the dimensionless geometry correction factor, $P_{\mathrm{c}}$ is the capillary pressure, $\mathrm{MPa}, \sigma$ is the surface tension of the liquid-gas interface, $\mathrm{N} / \mathrm{m}$, and $\theta$ is the contact angle.

We assume that a tight core has $n$ pores, and we can get a new modified H-P and L-Y equations for apparent viscosity of fluid in tight cores:

$$
\begin{aligned}
q_{\mathrm{a}} & =\frac{\sum n q_{i}}{n}=\frac{\pi\left(\alpha r_{\mathrm{a}}\right)^{4} \Delta P}{8 \mu_{\mathrm{c}} \tau L_{0}}=\frac{\pi r_{\mathrm{a}}^{4} \Delta P}{\xi 8 \mu \tau L_{0}}, \\
P_{\mathrm{ca}} & =\frac{\sum n P_{\mathrm{C}}}{n}=\frac{2 \sigma \cos \theta}{r_{\mathrm{a}}},
\end{aligned}
$$

where $r_{\mathrm{a}}$ is the average equivalent pore radius of the cores, $P_{\mathrm{ca}}$ is the average capillary pressure, $\mathrm{MPa}$, and $q_{\mathrm{a}}$ is the average flow rate, $\mathrm{m}^{3} / \mathrm{d}$.

According to the simultaneous connection of $\mathrm{H}-\mathrm{P}$ and Darcy equations, the average equivalent pore radius can be written as

$$
r_{\mathrm{a}}=\sqrt{\frac{8 K}{\phi}}
$$



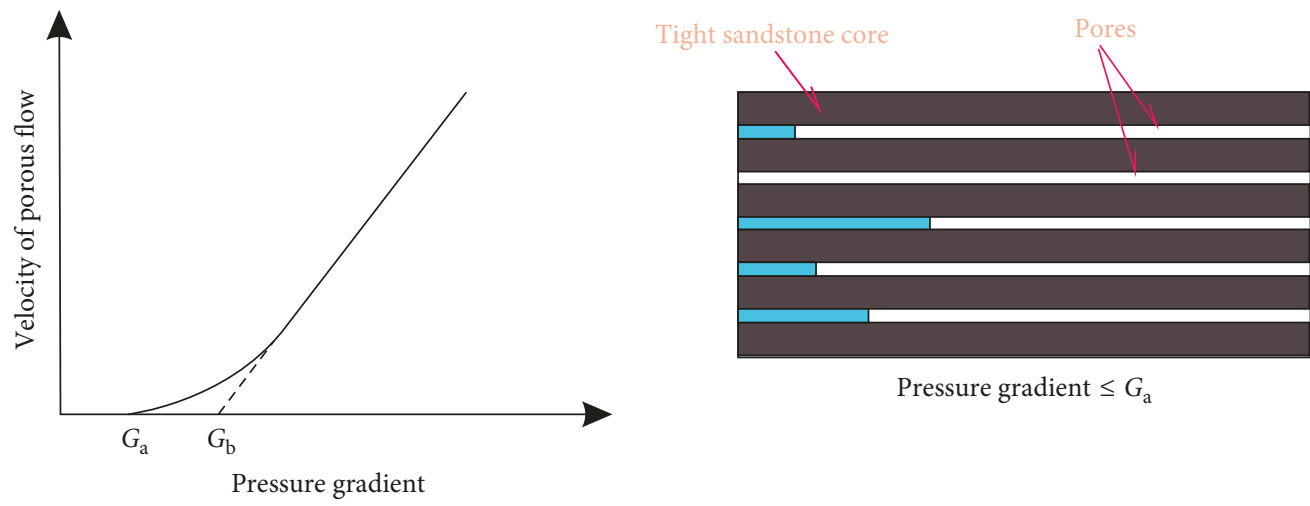

Pressure gradient $\leq G_{\mathrm{a}}$

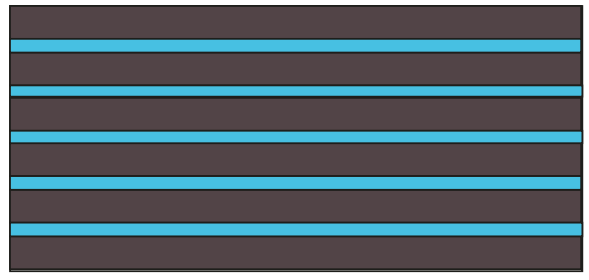

Pressure gradient $\geq G_{\mathrm{b}}$

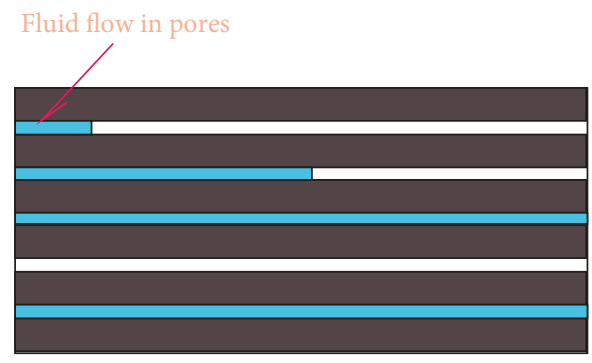

$G_{\mathrm{a}}<$ Pressure gradient $<G_{\mathrm{b}}$

Figure 1: Classical curve and diagram of nonlinear porous flow in tight cores under different pressure gradients.

3.2. Capillary Imbibition Model for Tight Porous Media. We assume that the tight core is equivalent to a cylinder consisting of $n$ tortuous, irregular cross-sectional capillary tubes. When the wetting liquid imbibes in the pore of the tight core, it will be subjected to capillary forces $\left(P_{\mathrm{ca}}\right)$, the hydrostatic pressure $\left(P_{\mathrm{ha}}\right)$, and the resistance of porous flow $\left(P_{\mathrm{Ga}}\right)$. We can calculate the total pressure drop in the following equation:

$$
\Delta P=P_{\mathrm{ca}}+P_{\mathrm{ha}}+P_{\mathrm{Ga}},
$$

where $P_{\mathrm{ha}}=\rho \mathrm{gL}_{0} \sin \psi$ and $P_{\mathrm{Ga}}=G L_{0}$.

Inserting Equation (5) into Equation (3):

$$
\begin{aligned}
q_{\mathrm{a}} & =\frac{\pi r_{\mathrm{a}}^{4} \Delta P}{8 \mu_{\mathrm{c}} \tau L_{0}(t)}\left[P_{\mathrm{ca}}+P_{\mathrm{ha}}(t)+P_{\mathrm{Ga}}(t)\right], \\
v(t) & =\frac{q}{\pi\left(\alpha r_{\mathrm{a}}\right)^{2}}=\frac{\pi r_{\mathrm{a}}^{2} \Delta P}{8 \mu_{\mathrm{c}} \tau L_{0}(t)}\left[\frac{2 \sigma \cos \theta}{r_{\mathrm{a}}}-\rho \mathrm{g} \sin \psi L_{0}(t)-G \tau L_{0}(t)\right] .
\end{aligned}
$$

According to equation $v(t)=d L(t) / d$, we can get the relation equation of the imbibition distance and imbibition time:

$$
\begin{aligned}
& \frac{\mathrm{d} L_{\mathrm{a}}(t)}{\mathrm{d} t}=\frac{r_{\mathrm{a}}^{2}}{8 \mu_{\mathrm{c}} \tau L_{0}(t)}\left[\frac{2 \sigma \cos \theta}{r_{\mathrm{a}}}-\rho \mathrm{g} \sin \psi L_{0}(t)-G \tau L_{0}(t)\right], \\
& \frac{\mathrm{d} L_{0}(t)}{\mathrm{d} t}=\frac{r_{\mathrm{a}} \sigma \cos \theta}{4 \mu_{\mathrm{c}} \tau^{2}} \frac{1}{L_{0}(t)}-\frac{r_{\mathrm{a}}^{2}(\rho \mathrm{g} \sin \psi+\tau G)}{8 \mu_{\mathrm{c}} \tau^{2}} .
\end{aligned}
$$

Rearranging Equation (7) gives

$$
\frac{\mathrm{d} L_{0}(t)}{\mathrm{d} t}=\frac{a}{L_{0}(t)}-b
$$

where

$$
\begin{aligned}
& a=\frac{r_{\mathrm{a}} \sigma \cos \theta}{4 \mu_{\mathrm{c}} \tau^{2}} \\
& b=\frac{r_{\mathrm{a}}^{2}(\rho \mathrm{g} \sin \psi+\tau G)}{8 \mu_{\mathrm{c}} \tau^{2}} .
\end{aligned}
$$

The relationship of $t$ - $h$ can be obtained through the integral of Equation (8):

$$
t=-\frac{L_{0}(t)}{b}-\frac{a}{b^{2}} \ln \left(1-\frac{b L_{0}(t)}{a}\right) .
$$

Due to the condition " $1-b L_{0}(t) / a>0$," we can know the maximum distance of imbibition is $L_{\max }=a / b$.

We can assume that when $L_{0}(t)=0.99 L_{\max }$, the total time of imbibition $t_{\max }$ can be calculated through substituting into Equation (10):

$$
t_{\max }=\frac{a}{b^{2}} \ln (-0.99-\ln (0.01)) \approx \frac{3.62 a}{b^{2}} .
$$

The Lambert $W$ is introduced to obtain an explicit analytical solution for Equation (7). The function $W(x)$ is defined by an inverse exponential function [18]:

$$
x=W(x) \mathrm{e}^{W(x)},
$$


where

$$
W(x) \approx \frac{2 e x-10.7036+7.56859 \sqrt{2+2 e x}}{12.7036+5.13501 \sqrt{2+2 e x}} \quad-e^{-1} \leq x \leq 0 .
$$

Therefore, the explicit analytical solution of Equation (8) can be obtained:

$$
L_{0}(\mathrm{t})=\frac{a}{b}\left[1+W\left(-e^{-1-\left(b^{2} / a\right) \mathrm{t}}\right)\right]
$$

where $e$ is Euler's number $(2.718282 . .$.$) .$

The accumulated weight of a wetting liquid imbibing into a tight core can be given by

$$
\begin{aligned}
M(t) & =\rho A \phi\left(S_{\mathrm{wf}}-S_{\mathrm{wi}}\right) L_{0}(t) \\
& =\frac{a}{b} \rho A \phi\left(S_{\mathrm{wf}}-S_{\mathrm{wi}}\right)\left[1+W\left(-\mathrm{e}^{-1-\left(b^{2} / a\right) t}\right)\right],
\end{aligned}
$$

where $\rho$ is the density of fluid, $\mathrm{kg} / \mathrm{m}^{3}, A$ is the cross-sectional area of the cores, $\mathrm{m}^{2}, \phi$ is the porosity, $S_{\mathrm{wf}}$ is the saturation of wetting liquid after imbibition, and $S_{\mathrm{wi}}$ is the initial saturation of wetting liquid.

\section{Results and Discussion}

4.1. Comparison and Analysis. Through research of the existing imbibition models, it is found that Cai's model, which takes into account the size and shape of pores, the tortuosity of imbibition streamlines in random porous media, and the initial wetting-phase saturation, is generalized and can be simplified to other models, such as FriesDreyer model [8]. However, because the resistance of imbibition is little in conventional porous media with relatively large pores, Cai's model omits the resistance term. As we all know, if there is no horizontal imbibition resistance in tight reservoirs, the distance of imbibition will be infinite, which is obviously unreasonable.

Therefore, based on Cai's model [8], our model considers the resistance of imbibition and the apparent viscosity of fluid in tight cores in order to apply in tight reservoirs. Fries-Dreyer model [18], Cai's model, and our model can be formed into " $d L / d t=a / L-b$ " mode. Table 1 shows the values of " $a$ and $b$ " in the mode.

Generally speaking, our model takes more geometrical parameters into account than other imbibition models in order to better match the real process of imbibition in tight cores. Accordingly, our model can derive other existing imbibition models under conditions of $G=0, \mu_{c}=\mu$ as well.

We choose tight sandstone data $\left(r_{\mathrm{a}}=1 \times 10^{-7} \mathrm{~m}\right.$, $\sigma=0.074 \mathrm{~N} \cdot \mathrm{m}, \theta=80^{\circ}, \mu_{\mathrm{c}}=1.08 \mathrm{cp}, \tau=2, G=0.43 \mathrm{MPa} / \mathrm{s}$, $\rho=1000 \mathrm{~g} / \mathrm{m}^{3}$, and $g=9.8 \mathrm{~m} / \mathrm{s}^{2}$ ) for calculation in these imbibition models at horizontal direction to quantitatively compare our model with the others.

As shown in Figure 2, since the Washburn Model and Fries-Dreyer Model do not take into account the tortuosity, the calculated value has a large gap with Cai's and our model's calculated value. The bigger the value of tortuosity is, the greater the difference is. Cai's model fits well in the initial stage of our model. However, since Cai's model does
TABLE 1: Values of " $a$ and $b$ " in " $d L / d t=a / L-b$ " mode.

\begin{tabular}{lccc}
\hline $\begin{array}{l}\text { Imbibition } \\
\text { model }\end{array}$ & Direction & $a$ & $b$ \\
\hline Washburn & Vertical & $r \sigma \cos \theta / 2 \mu$ & 0 \\
model & Horizontal & $r \sigma \cos \theta / 2 \mu$ & 0 \\
Fries-Dreyer & Vertical & $r \sigma \cos \theta / 4 \mu$ & $r^{2} \rho \mathrm{g} / 8 \mu$ \\
model & Horizontal & $r \sigma \cos \theta / 4 \mu$ & 0 \\
& Vertical & $r_{\mathrm{a}} \sigma \cos \theta / 4 \mu \tau^{2}$ & $r_{\mathrm{a}}^{2} \rho \mathrm{g} / 8 \mu \tau^{2}$ \\
Cai's model & Horizontal & $r_{\mathrm{a}} \sigma \cos \theta / 4 \mu \tau^{2}$ & 0 \\
& Vertical & $r_{\mathrm{a}} \sigma \cos \theta / 4 \mu_{\mathrm{c}} \tau^{2}$ & $r_{\mathrm{a}}^{2}(\rho \mathrm{g}+\tau G) / 8 \mu_{\mathrm{c}} \tau^{2}$ \\
Our model & Horizontal & $r_{\mathrm{a}} \sigma \cos \theta / 4 \mu_{\mathrm{c}} \tau^{2}$ & $r_{\mathrm{a}}^{2} G / 8 \mu_{\mathrm{c}} \tau$ \\
\hline
\end{tabular}

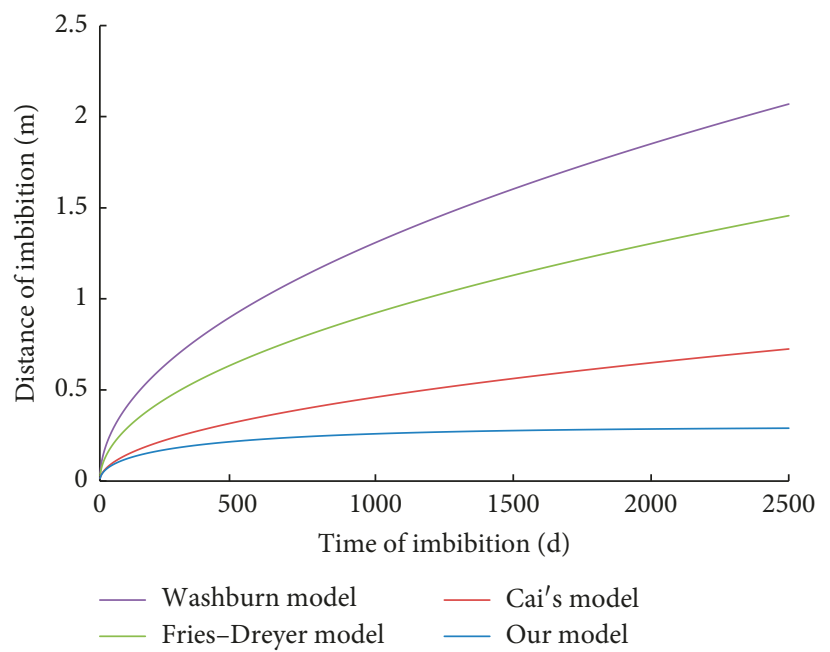

FIGURE 2: Quantitative comparison of our model to other models with tight sandstone data.

not consider the influence of resistance, there is no limit as the imbibition distance increases with imbibition time. As the imbibition continues, our model calculated curve tends to be flat, marking the end of the process of imbibition. Therefore, our model can be used for the calculation of the whole process of imbibition, especially in tight sandstone conditions.

4.2. Model Validation. When $G=0$ and $\mu_{\mathrm{c}}=\mu$, our model is same as Cai's model, which has been verified through porous materials with porosity of $0.045-0.7$ and permeability of 5-1200 mD.

The experimental data [32] of horizontal imbibition in tight cores $(k<1 \mathrm{mD})$ are collected to verify these models, and petrophysical parameters of tight cores for imbibition experiment are shown in Table 2.

It can be seen from Figure 3 that the result of FriesDreyer model has significant difference with the experimental data, and there is a good agreement between the result of Cai's model and the experimental data in the early time when $\tau=8$, but Cai's model cannot fit the experimental data at the later stage very well.

In our model, the comprehensive coefficient $(\zeta)$ is defined to be tortuosity $(\tau)$ multiplied with apparent viscosity coefficient $(\xi)$, which can characterize more influence 
TABle 2: Petrophysical parameters of tight cores for imbibition experiment.

\begin{tabular}{lccccccc}
\hline Number & $\begin{array}{c}\text { Diameter } \\
(\mathrm{cm})\end{array}$ & $\begin{array}{c}\text { Length } \\
(\mathrm{cm})\end{array}$ & $\begin{array}{c}\text { Porosity } \\
(\%)\end{array}$ & $\begin{array}{c}\text { Permeability } \\
(\mathrm{mD})\end{array}$ & Average radius $(\mathrm{m})$ & Density of fluid $\left(\mathrm{kg} / \mathrm{m}^{3}\right)$ & Viscosity of fluid $(\mathrm{MPa} \cdot \mathrm{s})$ \\
\hline Exp1 & 2.53 & 3.118 & 9.48 & 0.14 & 0.118 & 1000 & 1.183 \\
Exp2 & 2.52 & 2.794 & 5.85 & 0.215 & 0.294 & 1000 & 1.183 \\
Exp3 & 2.51 & 3.000 & 6.89 & 0.0229 & 0.026 & 1000 & 1.183 \\
\hline
\end{tabular}

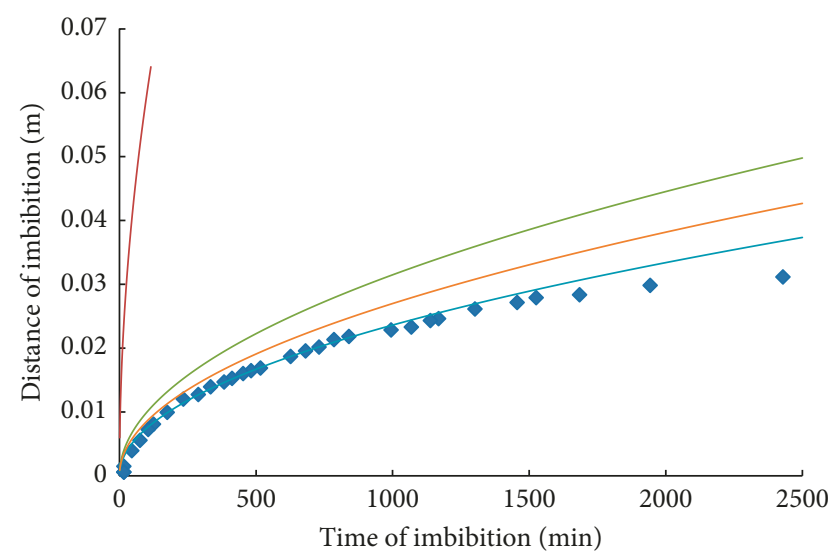

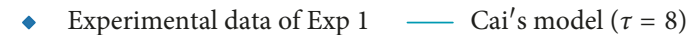

Fries-Dreyer model $(\tau=1) \quad$ Cai's model $(\tau=7)$

- Cai's model $(\tau=6)$

FIGURE 3: Variation of imbibition distance with imbibition time in tight cores: simulation results of Fries-Dreyer Model and Cai's Model with different tortuosity vs. experimental data of Exp1.

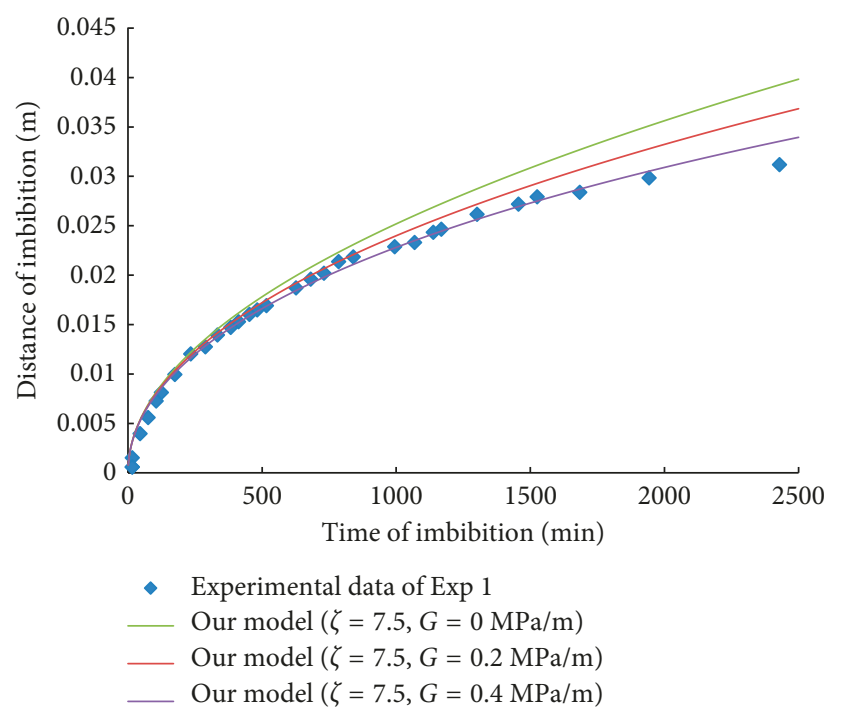

FIgURE 4: Variation of imbibition distance with imbibition time in tight cores: simulation results of our model with different composite factors $(\zeta)$ and fluid flow resistance $(G)$ vs. experimental data of Exp1.

parameters. Figure 4 shows that the result of our model $(\zeta=7.5$ and $G=0.4 \mathrm{MPa} / \mathrm{m})$ can fit the experimental data better than other models. We also verify our model by different experimental data, as shown in Figure 5. It can be known that the resistance $(G)$ is positively correlated with

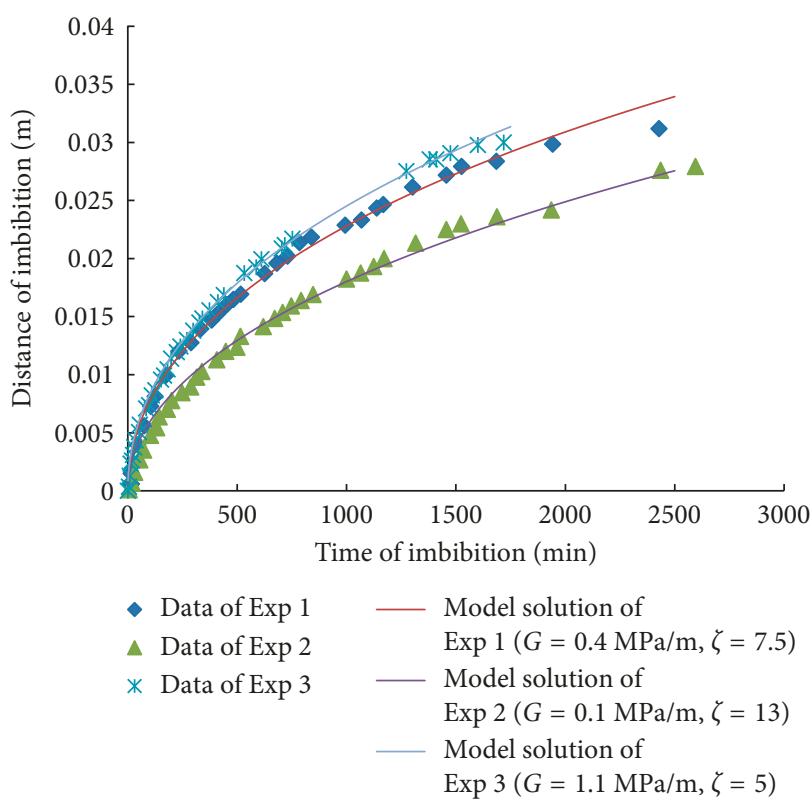

FIgURE 5: Comparison between imbibition experimental data of different tight cores and calculated results of our model under different composite factors $(\zeta)$ and fluid flow resistance $(G)$.

average radius, and the comprehensive coefficient $(\zeta)$ is negatively correlated with average radius.

As shown in Figure 6, it can be concluded that the resistance $(G)$ reduces the rate of imbibition, and the influence of resistance $(G)$ increases with the increase of imbibition time. Therefore, our model can fit the result of experiment better. According to Equation (14) and Exp3, we can predict that the total time of imbibition is 56 days and the maximum distance of imbibition is $0.09 \mathrm{~m}$ in corresponding tight reservoirs.

Due to a large amount of experimental data [33, 34], the empirical equation of imbibition resistance $(G)$ and average pores radius $\left(r_{\mathrm{a}}\right)$ can be written by

$$
G=M e^{N r_{\mathrm{a}}}
$$

where $M$ and $N$ are the empirical constants. According to experimental data of Exp1, 2, and 3 and their fitting data with our model, we can obtain the $M=3.2347$ and $N=-2 \times 10^{7}$.

When the imbibition resistance $(G)$ is not considered, the smaller the average pore radius $(r)$ is, the slower the imbibition will be, and the imbibition distance is unlimited. When the imbibition resistance $(G)$ is considered, as shown in Figure $7(\mathrm{a})$, in the early stage of imbibition, the smaller the average pore radius $(r)$ is, the slower the imbibition will 


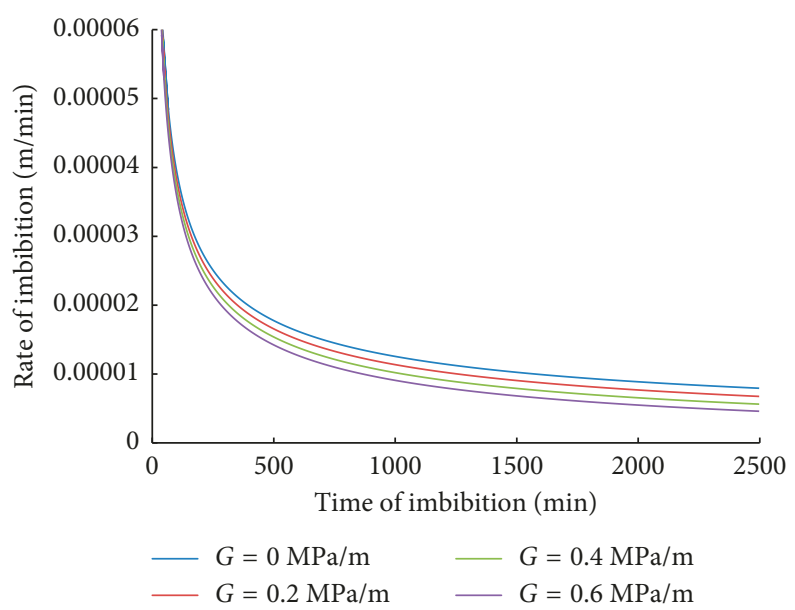

FIGURE 6: The variation curves of imbibition rate with imbibition time under different fluid flow resistances $(G)$ in tight porous media.

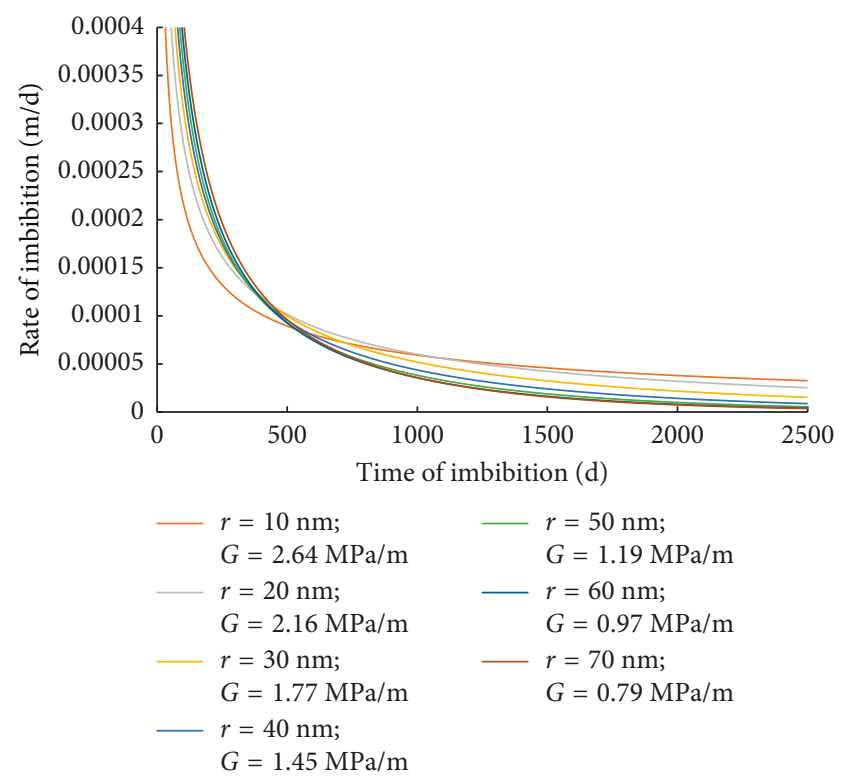

(a)

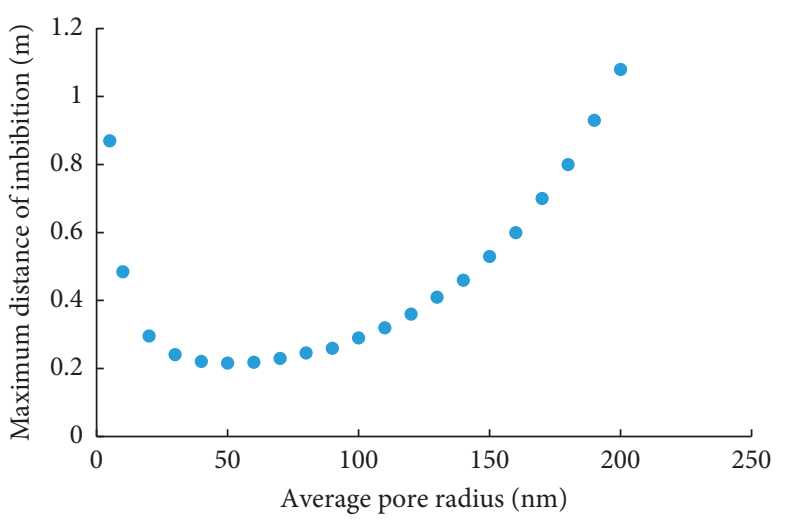

(b)

FIGURE 7: The variation curves of imbibition rate with imbibition time under different average pore radius $(r)$ and the curve maximum distance of imbibition with average pore radius.

be. The early stage of imbibition is mainly controlled by capillary force. In the middle and late stages of imbibition, as the imbibition distance increases, the imbibition resistance enhances, and the rate of imbibition gradually slows down. According to Equation (3) and Equation (16), the smaller the average pore radius $(r)$ is, the bigger the capillary force and the imbibition resistance will be. The stronger the capillary force relative to the imbibition resistance, the smaller the deceleration of imbibition rate will be. Figure 7 (b) shows that when the average pore radius is more than $50 \mathrm{~nm}$, the maximum imbibition distance increases as the average pore radius increases; when the average pore radius is less than $50 \mathrm{~nm}$, the maximum imbibition distance increases as the average pore radius decreases. Therefore, the imbibition is common controlled by capillary force and imbibition resistance during the middle and late stages of imbibition.

\section{Conclusions}

In this paper, a more generalized capillary imbibition model is derived by considering the resistance and the apparent viscosity of fluids in porous media. This model takes more geometrical parameters into account than other imbibition models to better match the result of imbibition experiment in tight cores and can derive other existing imbibition models in special cases. Through this mode and experimental data, we can predict the maximum distance and total time of imbibition of water in tight reservoirs, which will facilitate the study on water injection development in tight oil and gas reservoirs. 


\section{Data Availability}

We declared that materials described in the manuscript, including all relevant raw data, will be freely available to any scientist wishing to use them for noncommercial purposes, without breaching participant confidentiality.

\section{Conflicts of Interest}

The authors declare that they have no conflicts of interest.

\section{Acknowledgments}

This work was kindly supported by the National Science and Technology Major Project of China (2017ZX05013-001) and the Key Science and Technology Project of PetroChina (2016B-1304).

\section{References}

[1] J. O. Alvarez and D. Schechter, "Application of wettability alteration in the exploitation of unconventional liquid resources," Petroleum Exploration and Development, vol. 43, no. 5, pp. 832-840, 2016.

[2] P. Kathel and K. K. Mohanty, "Wettability alteration in a tight oil reservoir," Energy and Fuels, vol. 27, no. 11, pp. 6460-6468, 2013.

[3] J. O. Alvarez and D. Schechter, "Wettability alteration and spontaneous imbibition in unconventional liquid reservoirs by surfactant additives," SPE Reservoir Evaluation and Engineering, vol. 20, no. 1, pp. 107-117, 2016.

[4] Y. G. Shen, M. M. Meng, T. Liu, H. K. Ge, and Y. L. Zhang, "Impact of petrophysical properties on hydraulic fracturing and development in tight volcanic gas reservoirs," Geofluids, vol. 2017, Article ID 5235140, 13 pages, 2017.

[5] R. Song, M. M. Cui, J. J. Liu, P. G. Ranjith, and Y. Lei, “A porescale simulation on thermal-hydromechanical coupling mechanism of rock," Geofluids, vol. 2017, Article ID 7510527 , 12 pages, 2017.

[6] N. R. Morrow and G. Mason, "Recovery of oil by spontaneous imbibition," Current Opinion in Colloid and Interface Science, vol. 6, no. 4, pp. 321-337, 2001.

[7] M. J. Alava, M. Dube, and M. Rost, "Imbibition in disordered media," Advances in Physics, vol. 53, no. 2, pp. 83-175, 2004.

[8] J. C. Cai, E. Perfect, C. L. Cheng, and X. Y. Hu, "Generalized modeling of spontaneous imbibition based on hagenpoiseuille flow in tortuous capillaries with variably shaped apertures," Langmuir, vol. 30, no. 18, pp. 5142-5151, 2014.

[9] K. Liu, Z. Y. Lin, D. Y. Gao, and Y. C. Wei, "Mathematical model for the fluid-gas spontaneous displacement in nanoscale porous media considering the slippage and temperature," Mathematical Problems in Engineering, vol. 2018, Article ID 3245498, 8 pages, 2018.

[10] W. Lin, X. Z. Li, Z. M. Yang et al., "Construction of dual pore 3-D digital cores with a hybrid method combined with physical experiment method and numerical reconstruction method," Transport in porous media, vol. 120, no. 1, pp. 227-238, 2017.

[11] R. Song, J. J. Liu, and M. M. Cui, "A new method to reconstruct structured mesh model from micro-computed tomography images of porous media and its application," International Journal of Heat and Mass Transfer, vol. 109, pp. 705-715, 2017.
[12] J. M. Bell and F. K. Cameron, "The flow of liquids through capillary spaces," Journal of Physical Chemistry, vol. 10, no. 8, pp. 658-674, 1905.

[13] R. Lucas, "Ueber das zeitgesetz des kapillaren aufstiegs von flussigkeiten," Kolloid-Zeitschrif, vol. 23, no. 1, pp. 15-22, 1918.

[14] E. W. Washburn, "Dynamics of capillary flow," Physical Review, vol. 17, no. 3, pp. 273-283, 1921.

[15] F. A. L. Dullien, M. S. El-Sayed, and V. K. Batra, "Rate of capillary rise in porous media with nonuniform pores," Journal of Colloid and Interface Science, vol. 60, no. 3, pp. 497-506, 1977.

[16] C. Hammecker, J. D. Mertz, C. Fischer, and D. Jeannette, “A geometrical model for numerical simulation of capillary imbibition in sedimentary rocks," Transport in Porous Media, vol. 12, no. 2, pp. 125-141, 1993.

[17] D. Benavente, P. Lock, M. Á. G. D. Cura, and S. Ordóñez, "Predicting the capillary imbibition of porous rocks from microstructure," Transport in Porous Media, vol. 49, no. 1, pp. 59-76, 2002.

[18] N. Fries and M. Dreyer, "An analytic solution of capillary rise restrained by gravity," Journal of Colloid and Interface Science, vol. 320, pp. 259-263, 2008.

[19] J. C. Cai, B. M. Yu, M. Q. Zou, and L. Luo, "Fractal characterization of spontaneous co-current imbibition in porous media," Energy and Fuels, vol. 24, no. 3, pp. 1860-1867, 2010.

[20] J. C. Cai, S. L. Guo, L. J. You, and X. Y. Hu, "Fractal analysis of spontaneous imbibition mechanism in fractured-porous dual media reservoir," Acta Physica Sinica, vol. 62, no. 1, article 014701, 2013.

[21] J. C. Cai and B. M. Yu, "Advances in studies of spontaneous imbibitions in porous media," Advances in Mechanics, vol. 42, pp. 735-754, 2012.

[22] Y. Z. Huang, Z. M. Yang, Y. He, X. W. Wang, and Y. T. Luo, "Nonlinear porous flow in low permeability porous media," Mechanics in Engineering, vol. 35, no. 5, pp. 1-8, 2013.

[23] R. J. Miller and P. F. Low, "Threshold gradient for water flow in clay systems," Soil Science Society of America Journal, vol. 27, no. 6, pp. 605-609, 1963.

[24] Z. M. Yang, Z. Z. Ma, Y. T. Luo, Y. P. Zhang, H. K. Guo, and W. Lin, "A measured method for in-situ viscosity of fluid in porous media by nuclear magnetic resonance," Geofluids, vol. 2018, Article ID 9542152, 8 pages, 2018.

[25] R. M. Fand, B. Y. K. Kim, A. C. C. Lam, and R. T. Phan, "Resistance to the flow of fluids through simple and complex porous media whose matrices are composed of randomly packed spheres," Journal of Fluids Engineering, vol. 109, no. 3, pp. 268-273, 1987.

[26] S. J. Liu and J. H. Masliyah, "Single fluid flow in porous media," Chemical Engineering Communications, vol. 148-150, no. 1, pp. 653-732, 2010.

[27] R. Song, M. M. Cui, and J. J. Liu, "Single and multiple objective optimization of a natural gas liquefaction process," Energy, vol. 124, pp. 19-28, 2017.

[28] R. Song, M. M. Cui, and J. J. Liu, "A correlation for heat transfer and flow friction characteristics of the offset strip fin heat exchanger," International Journal of Heat and Mass Transfer, vol. 115, pp. 695-705, 2017.

[29] C. Z. Jia, M. Zheng, and Y. F. Zhang, "Unconventional hydrocarbon resources in China and the prospect of exploration and development," Petroleum Exploration and Development, vol. 39, no. 2, pp. 129-135, 2012.

[30] L. Ren, Y. L. Su, and G. Y. Zhao, "Non-Darcy flow pattern response and critical well spacing in tight oil reservoirs," 
Journal of Central South University (Science and Technology), vol. 46, no. 5, pp. 1732-1738, 2015.

[31] Y. J. Gong, S. B. Liu, L. Jiang, X. J. Yuan, and S. Z. Tao, "Experimental study of seepage characteristic and mechanism in tight gas sands: a case from Xujiahe Reservoir of Sichuan Basin," Natural Gas Geoscience, vol. 25, no. 6, pp. 804-809, 2014.

[32] P. Gao, Experimental Study on Permeability and Absorption Characteristics Sandstone Reservoir - In Y Tight Gas Reservoir and H Tight Reservoir as an Example, Master of Science, Xi'an Shiyou University, Xi'an, China, 2016.

[33] Z. M. Yang, Y.Z. Zhang, M. Q. Hao, X. G. Liu, and W. W. Shan, "Comprehensive evaluation of reservoir in lowpermeability oilfields," Acta Petrolei Sinica, vol. 27, no. 2, pp. 64-67, 2006.

[34] Z. H. Zhang, Z. M. Yang, X. G. Liu, W. Xiong, and X. W. Wang, "A grading evaluation method for lowpermeability reservoirs and its application," Acta Petrolei Sinica, vol. 33, no. 3, pp. 437-441, 2012. 


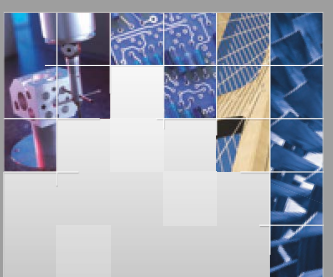

\section{Enfincering}
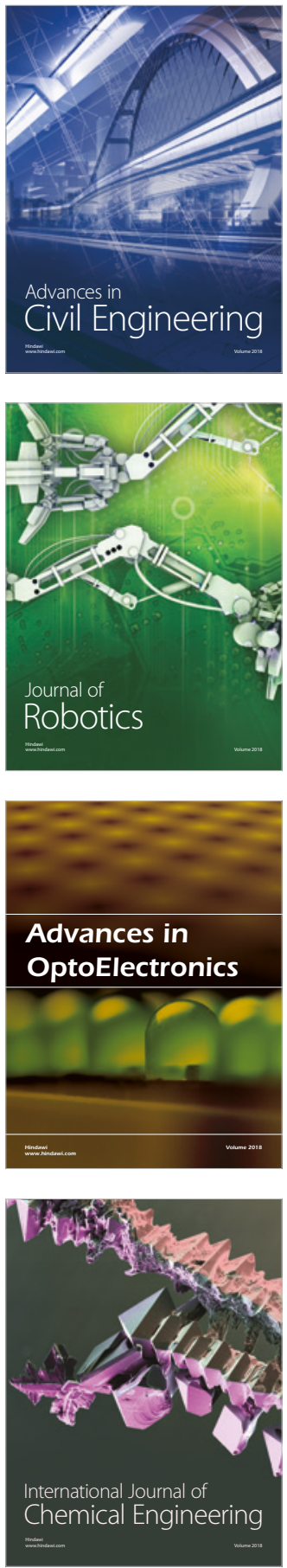

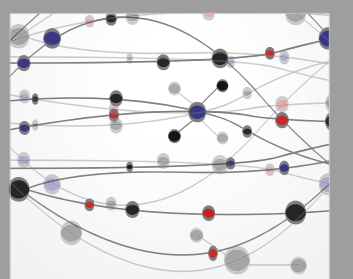

\section{Rotating \\ Machinery}

The Scientific World Journal

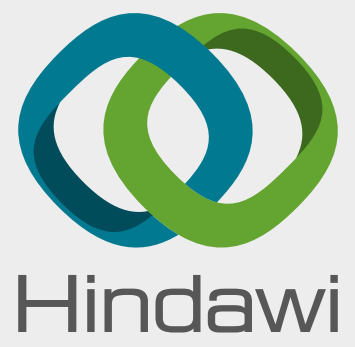

Submit your manuscripts at

www.hindawi.com
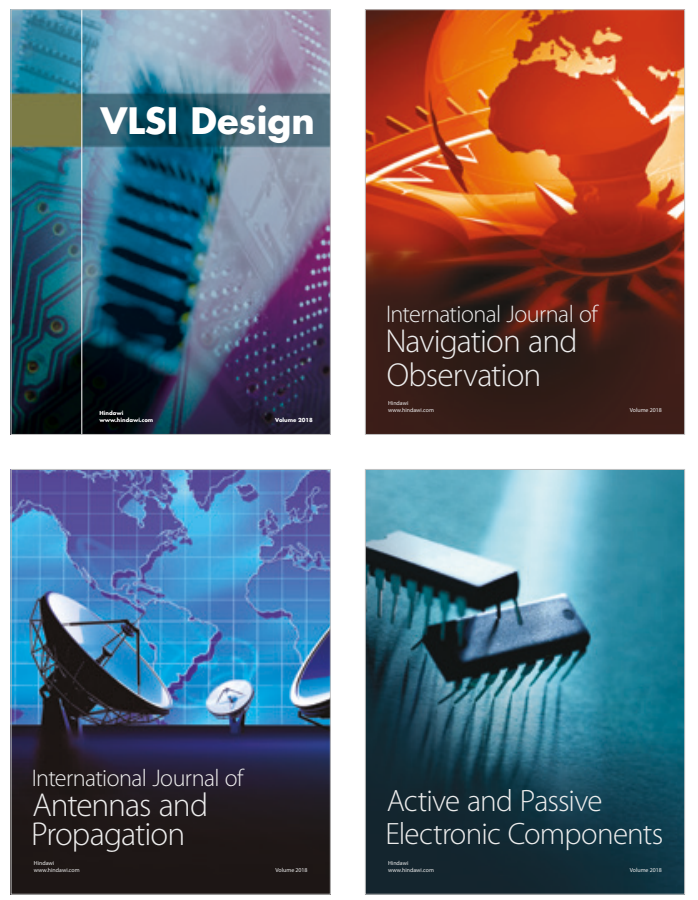
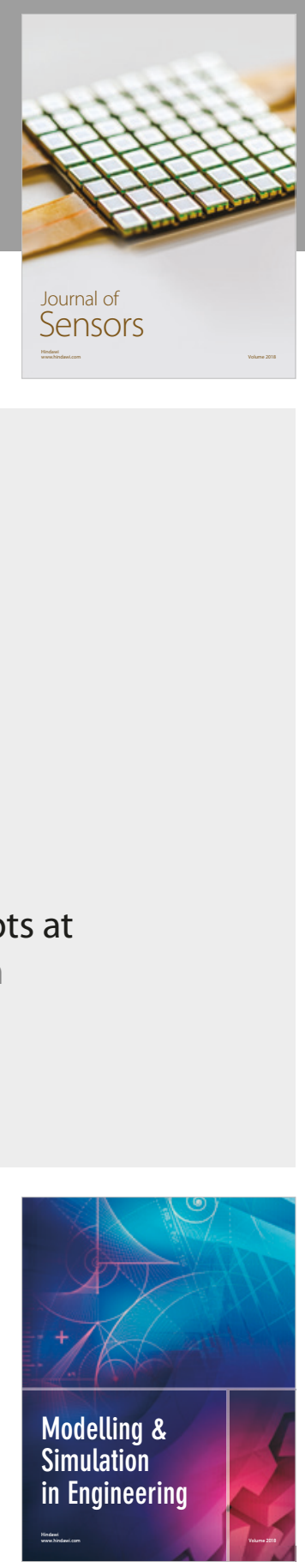

\section{Advances \\ Multimedia}
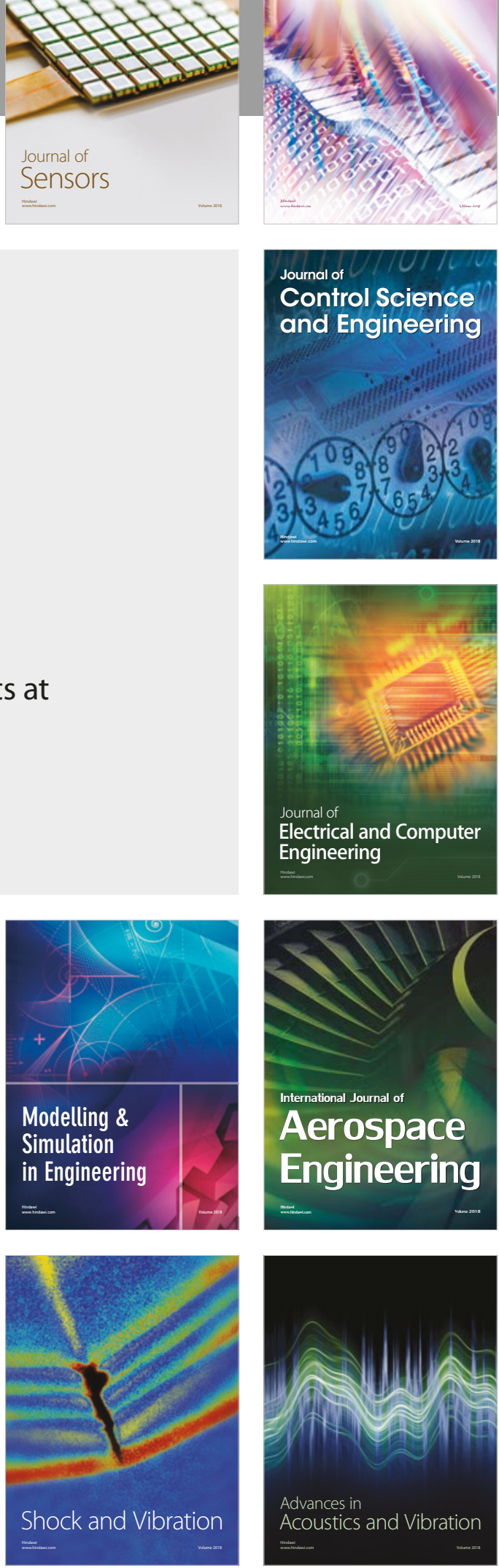